\title{
Effective Communication during a Global Health Crisis: A Content Analysis of Presidential Addresses on the COVID-19 Pandemic in Ghana
}

\section{Prince Adu Gyamfi' ${ }^{\oplus}$ and Adwoa Sikayena Amankwah ${ }^{2} \odot$}

1. College of Liberal Arts, Purdue University, West Lafayette, IN, USA

2. University of Professional Studies, Accra (UPSA), Ghana

\begin{abstract}
The COVID-19 pandemic is causing incessant disruption to the social and economic lives of societies. Public health and crisis communicators have recommended some best practices in crisis and emergency risk messaging for effective health messages during pandemics. Thus, this study utilized seven crisis and emergency risk messaging best practices to qualitatively analyze 14 speeches delivered by the Ghanaian President on the COVID-19 pandemic in the country to demonstrate how the speeches conveyed information about the pandemic to the public. The study found that all seven best practices (i.e., explain what is known, explain what is not known, explain how or why the event happened, promote action steps, express empathy, express accountability, and express commitment) were demonstrated in all the 14 speeches. Implications for practice are discussed.
\end{abstract}

KEYWORDS: public health messages, crisis communication, risk communication, COVID-19, presidential addresses

The global coronavirus disease (COVID-19) continues to have a serious impact on social and economic activities (World Health Organization [WHO], 2020). As many as 215 countries and territories have recorded COVID-19 cases (Centers for Disease Control and Prevention [CDC], 2020); and over 104 million

CONTACT Prince Adu Gyamfi (D) - E-mail: padugyam@purdue.edu • College of Liberal Arts • Purdue University • 100 North University Street • West Lafayette, IN 47907, USA 
confirmed cases and 2 million deaths have been reported globally, and new cases and deaths are reported each day (WHO, 2021). Thus, to contain the spread of COVID-19, countries have put in place stringent public health and social measures such as limitations on domestic and international travels, stay-at-home orders, and closing down of schools, shops, and religious centers (WHO, 2020). This global pandemic has the characteristics of both risk and crisis. As a risk, the COVID-19 pandemic threatens things people value such as social and religious gatherings including economic activities (Fischhoff \& Kadvany, 2011) and also brings uncertainties about "questions over the incubation period, infectivity before symptoms, seasonal dimensions, the specificity of the disease for certain population groups, re-infection rates, and perhaps most importantly, the mortality rate" (Balog-Way \& McComas, 2020, p. 839). Also, as a crisis, it is unanticipated and widespread, threatens priority goals, and requires rapid response to attenuate harm (T. L. Sellnow \& Seeger, 2013).

Communication, particularly public health communication, plays an important role in protecting public health during pandemics (B. Reynolds \& Seeger, 2005), and such "communications must successfully instruct, inform, and motivate appropriate self-protective behaviors; update risk information; build trust in officials; and dispel rumors" (Vaughan \& Tinker, 2009, p. 324). Due to the important role public health communication plays during pandemics, governments of countries affected by the COVID-19 pandemic have been providing information through public addresses to their citizens about what to do and measures undertaken to contain the spread of the virus. For instance, when the WHO officially declared COVID-19 a global pandemic in March, the president of Ghana, Nana Akufo Addo, immediately addressed the nation about measures undertaken by the government even though then the country was yet to record a COVID-19 case. According to crisis communicators, this timely information from the president served to prepare and ready the public for the COVID-19 pandemic occurrence in the country (Coombs, 2009; T. L. Sellnow, 2015). T. L. Sellnow (2015) articulates that providing information to the public (i.e., stakeholders) during the pre-crisis phase can potentially diminish the harm caused by the crisis. 
Between March 2020 and January 2021, the president has delivered 23 public addresses on the pandemic, and the country has recorded over 68,559 cases and 433 deaths (WHO, 2021).

Communication scholars have developed risk and crisis communication theories and models that "outline factors necessary for successful communication at different phases of crisis or emergency response" (Parmer et al., 2016, p. 1215). While risk and crisis communication were originally distinct subfields, they have evolved to be more interactive, culminating into an integrative model called the crisis and emergency risk communication (CERC) (Palenchar, 2009; B. Reynolds, 2002; B. Reynolds \& Quinn, 2008; Veil et al., 2008). The CERC model has been applied in public health contexts such as the $\mathrm{H}_{1} \mathrm{~N}_{1}$ influenza pandemic (B. Reynolds \& Quinn, 2008; Seeger et al., 2009), Hurricane Katrina (Vanderford et al., 2007), and Hurricane Maria in Puerto Rico (Andrade et al., 2020). Previous studies have recommended best practices for developing and disseminating messages during crises or disasters (Parmer et al., 2016; D. D. Sellnow et al., 2019; T. Sellnow \& Sellnow, 2010). For example, D. D. Sellnow and colleagues (2017) empirically tested the IDEA (internalization, distribution, explanation, action) model in the domain of food contamination recalls and found that the IDEA model messages were more effective than control messages in motivating participants to engage in selfprotective behaviors. However, the IDEA model does not include the elements of accountability and commitment which are considered important components of crisis and risk messages (CDC, 2014; B. J. Reynolds, 2011). Parmer and colleagues (2016) have extended the CERC model, particularly the content dimension, to develop seven best practices of crisis and emergency risk messages. This modified version of the CERC model captures accountability and commitment components, making it more comprehensive than the IDEA model as a crisis and risk message design framework. Thus, the present study utilized Parmer et al's version of the CERC model as its framework. Parmer et al. used these best practices to examine media coverage of foodborne epidemics and natural disasters and found that six of the seven best practices appeared in less than $25 \%$ of stories. Their findings further revealed that information communicated to the public about the foodborne illness 
outbreak was different from those of natural disaster events. Specifically, foodborne illness outbreak stories exhibited more best practices of crisis and emergency risk messages than natural disaster stories. However, their study has several limitations of which the current study seeks to remedy.

First, their study focused on media content which might be different from the content of presidential public addresses because media content is primarily influenced by journalistic values such as prominence, proximity, currency, timeliness, conflict, human interest, and bizarreness (Boyd, 1994). These journalistic values influence how media cover crises and emergencies. Thus, this study seeks to utilize these seven best practices to investigate the president's public addresses on the COVID-19 pandemic in Ghana. More precisely, it is unclear whether these public addresses follow the best practices that are recommended to make messages most effective for protecting public health during an emergency or crisis. Second, their study focused on story length and the total number of best practices per story but did not examine qualitatively how these best practices were used in news stories. Thus, the present study adds to the literature on the crisis and emergency risk messaging best practices by employing a qualitative approach (i.e., thematic analysis) to examine how these seven best practices are used in the public addresses to convey information about the pandemic to the public. Lastly, their study focused on foodborne illness outbreak and natural disaster contexts which are different from the COVID-19 pandemic as their findings showed differences between foodborne illness outbreak stories and natural disaster stories (i.e., foodborne illness stories had more best practices than natural disaster stories). The purpose of this study is to provide practical guidelines for public health and crisis communicators on how to develop and disseminate effective public health messages through presidential public addresses to inform the public about what to do to protect themselves during pandemics. We first review existing literature focusing on the crisis and risk communication models. We then describe the research questions and present a thematic content analysis study. 


\section{The Crisis and Emergency Risk Communication (CERC) Model}

After the events of 9/11 and the anthrax crises, the CDC recognized that a more integrative approach to risk, crisis, and emergency response communication was needed "in an era of bioterrorism as well as other emerging global threats to public health" (B. Reynolds \& Seeger, 2005, p. 49). Hence, the crisis and emergency risk communication (CERC) model was developed. This model, which is practice-oriented, has both process and content dimensions (Parmer et al., 2016). Whereas the process dimension evaluates the crisis or emergency and designs response to events unfolding at five different phases of the crisis: pre-crisis, initial event, maintenance, resolution, and evaluation (CDC, 2014; Quinn, 2008; T. L. Sellnow \& Seeger, 2013), the content dimension conveys "information to the public at large and the affected parties" (Parmer et al., 2016, p. 1215). The current study focuses on the content dimension.

Seeger (2006) argues, "Best practices are useful for packaging learned principles in a way that facilitates their communication both within and between organizations and, ultimately, their adoption" (p. 233). Thus, Seeger (2006) has recommended ten best practices for effective crisis communication: (1) process approaches and policy development; (2) pre-event planning; (3) partnership with the public; (4) listen to the public's concerns and understand the audience; (5) honesty, candor, and openness; (6) collaborate and coordinate with credible sources; (7) meet the needs of the media and remain accessible; (8) communicate with compassion, concern, and empathy; (9) accept uncertainty and ambiguity; and (10) messages of self-efficacy. Seeger (2006) argues, "Messages of self-efficacy are most effective when they have specific characteristics" (p. 242). Some of these message characteristics include specific harm-reducing actions, what can be done to help others, and a range of activities. These messages of self-efficacy should contain clear and meaningful actions and be consistent as well (Seeger, 2006). However, the messages of self-efficacy best practice have some limitations. They do not express empathy, care, and compassion for people affected by the crisis or the disaster. Also, they do not express commitment and accountability. All these components are crucial for designing effective crisis and risk messages. 


\section{The Internalization, Distribution, Explanation, and Action (IDEA) Model}

Crisis communicators strongly recommend the dissemination of instructional messages to the public during crises or emergencies (Coombs, 2009; T. L. Sellnow, 2015). According to Coombs, instructional information should seek to tell the target audience what they need to do to protect themselves from the crisis. Specifically, scholars like Mileti, Fitzpatrick, and Sorensen articulate that such messages must meet two basic criteria (T. L. Sellnow, 2015). First, the message must be accessible to the public. Second, the message must account for limitations in literacy and numeracy among the target population, so the content of the message is easily understood by all. In this regard, T. L. Sellnow and Sellnow (2013) have developed the IDEA model for designing effective instructional risk and crisis messages. The IDEA model, which is grounded in experiential learning, has four aspects: internalization, distribution, explanation, and action. The internalization, explanation, and action aspects focus on message content, and the distribution aspect focuses on channels through which messages are sent. Internalization messages express care, compassion, and the impact of the crisis. Explanation messages address what is happening and why, and what is being done in response. Finally, action messages recommend specific action steps to take or not take to protect oneself and/or loved ones. Previous studies have empirically tested the IDEA model in the domain of food contamination (Escherichia coli) outbreak in ground beef and blended meat (D. D. Sellnow et al., 2015; D. D. Sellnow et al., 2017; D. D. Sellnow et al., 2019). The findings consistently show that the IDEA model is an effective instructional risk and crisis message design framework.

However, the IDEA model lacks breadth as it overlooks the elements of accountability and commitment which are crucial for designing crisis and risk messages. Extending the CERC model, particularly its content dimension, Parmer et al. (2016) have developed seven best practices for designing crisis and emergency risks messages. These practices are: 
Explain what is known at the time about the events' impact on human health; explain what is not known about the threat to human health; explain how or why the event happened; promote action steps the reader or viewer can take to reduce the personal threat; express empathy about the threat to human health; express accountability; and express commitment. (Parmer et al., 2016, p. 1216)

Parmer et al.s (2016) seven best practices are the most comprehensive; therefore, their modified version of the CERC model provided the framework for the present study. The following research questions guided this study:

RQ1: What crisis and emergency risk messaging best practices are demonstrated in the public addresses of the Ghanaian president on the COVID-19 pandemic?

RQ2: How are the crisis and emergency risk messaging best practices used in the public addresses of the Ghanaian president to convey information about the COVID-19 pandemic to the public?

\section{Method}

The study used a basic qualitative research approach to analyze the content of public addresses or speeches of the Ghanaian president about the COVID-19 pandemic in Ghana. As the researchers were interested in understanding how the president's speeches constructed and conveyed meanings about the pandemic, this research approach was most appropriate to "uncover and interpret these meanings" (Merriam \& Tisdell, 2016, p. 25). The president's public addresses were chosen as this study's data for three reasons. First, these public addresses served as direct sources of information about updates on the pandemic and measures taken to control the spread of the virus for both the media and the general public in the country. The implication was that these speeches were influencing the media agenda on COVID-19 related issues as well as shaping the general public's perception of the pandemic in the country. Second, these speeches were easily accessible as public documents for analysis. Third, studies focusing on crisis and emergency risk messaging are mostly conducted among populations in developed 
countries with little or no studies on developing countries like Ghana. According to Henrich et al. (2010), most behavioral science studies have heavily relied on samples from Western, educated, industrialized, rich, and democratic (WEIRD) populations; and this heavy reliance "may cause researchers to miss important dimensions of variations, and devote undue attention to behavioral tendencies that are unusual in a global context" (p. 80). Thus, the unit of analysis for this study was the public address of the Ghanaian president about the COVID-19 pandemic in Ghana.

\section{Sampling and Data Analysis}

The president has delivered a total number of 23 speeches about the pandemic between March 2020 and January 2021; that is a period of 11 months. However, this study selected 14 speeches that were consecutively delivered between March 11 and July 26 as its sample because the number of the COVID-19 cases increased significantly in the country between those 5 -month periods. These 14 speeches were 60 single-spaced pages of text-a total of 27,732 words. Before the data analysis, the first and second authors met to discuss the data analysis method and procedures that would be most effective for answering this study's research questions. Thus, Braun and Clarke's (2006) six steps for conducting thematic analysis were utilized. This thematic analysis enabled the researchers to identify, analyze, and report themes within the data (Braun \& Clarke, 2006). The authors independently analyzed the data. According to Lincoln and Guba (1985), the use of different investigators (referred to as the technique of triangulation) during data analysis in qualitative research boosts "the probability [those] findings" (p. 305) and enhances the credibility of interpretations. To make sure that the study's research questions were adequately answered, the seven crisis and emergency risk messaging best practices developed by Parmer et al. (2016) guided the analysis. These seven practices included "explain what is known," "explain what is not known," "explain how or why the event happened," "promote action steps," "express empathy," "express accountability," and "express commitment." 
First, all the 14 speeches were retrieved in Word documents, and each researcher read and reread these speeches to familiarize themselves with the data. During this immersion stage, notes were taken to produce a list of ideas. Second, this list of ideas was used to generate initial codes from the data. The data was coded around the crisis and emergency risk messaging best practices. Coding was manually done by using highlighters to "indicate potential patterns" (Braun \& Clarke, 2006, p. 89). A list of different codes was produced. Third, different codes were sorted into potential themes. For example, codes sharing similar meanings were grouped and were given a common name or term to differentiate one group of codes from another group of codes. At the fourth stage, the researchers met to discuss the initial themes they had each identified. The researchers reviewed these initially identified themes together to ensure that each theme reflected the crisis and emergency risk messaging best practices. They settled on 12 themes and finally merged them into three overarching themes: health, sociocultural, and economic dimensions. Lastly, some rich, thick excerpts from the data were included in the write-up of the report to boost the credibility of this study's findings (Miles \& Huberman, 1994).

\section{Results}

The results showed that all the seven best practices of crisis and emergency risk messaging recommended by Parmer and others (2016) were present in all the 14 presidential addresses. See Table 1 for which types of addresses each best practice appeared in. The "explain what is known" and "promote action steps" best practices were demonstrated in all the 14 speeches. Accountability best practice appeared in 13 of the 14 speeches. The "express empathy" and "express commitment" best practices appeared in 11 of the 14 speeches delivered by the Ghanaian president. Finally, the "explain how or why the pandemic happened" and "explain what is not known" best practices appeared in 2 of the 14 speeches. The results also revealed that at least three best practices were present in every speech that the Ghanaian president delivered on the COVID-19 pandemic. 


\section{TABLE 1 Types of Addresses Each Best Practice Appeared In}

\begin{tabular}{|l|l|}
$\begin{array}{l}\text { Types of } \\
\text { Address }\end{array}$ & Best Practices \\
\hline Update No.1 & $\begin{array}{l}\text { Explain what is known; Promote action steps; Express } \\
\text { accountability }\end{array}$ \\
Update No. 2 & $\begin{array}{l}\text { Explain what is known; Promote action steps; Express } \\
\text { empathy; Express accountability; Express commitment }\end{array}$ \\
Update No.3 & $\begin{array}{l}\text { Explain what is known; Promote action steps; Express } \\
\text { empathy; Express accountability; Express commitment }\end{array}$ \\
Update No.5 & $\begin{array}{l}\text { Explain what is known; Promote action steps; Express } \\
\text { empathy; Express accountability; Express commitment }\end{array}$ \\
Update No.6 & $\begin{array}{l}\text { Explain what is known; Promote action steps; Express } \\
\text { empathy; Express accountability }\end{array}$ \\
Update No.7 & $\begin{array}{l}\text { Explain what is known; Promote action steps; Express } \\
\text { Explain what is known; Explain what is not known; } \\
\text { Explain how or why; Promote action steps; Express } \\
\text { empathy; Express accountability; Express commitment }\end{array}$ \\
Update No.8 & $\begin{array}{l}\text { Explain what is known; Explain how or why; Promote } \\
\text { action steps; Express accountability }\end{array}$ \\
Update No.9 & $\begin{array}{l}\text { Explain what is known; Promote action steps; Express } \\
\text { empathy; Express commitment }\end{array}$ \\
Uxplain what is known; Promote action steps; Express \\
Update No. 10
\end{tabular}


The thematic analysis of the 14 speeches produced 12 concepts aligned with the seven action steps in the CERC model. These concepts were merged into three main themes: health, sociocultural, and economic dimensions.

\section{Health Dimension}

Three subthemes emerged to promote action steps on health that the reader or viewer could take to reduce their threat: personal hygiene, mask-wearing, and healthy lifestyle. In terms of what was known at the time about the pandemic's impact on human health, two subthemes emerged: prevalence and severity of the virus. One subtheme emerged to explain how or why the pandemic happened: the importation of the virus.

Personal hygiene. This subtheme reflected actions that individuals, groups, and organizations could take to reduce personal and corporate threats. These speeches recommended personal and regular washing of hands with soap under running water, using alcohol-based sanitizers after using public facilities, and keeping reusable face masks clean, while promptly disposing of disposable ones after use. Groups providing public services such as public transport owners were also required to observe enhanced hygiene protocols by providing the required amenities.

Mask-wearing. This consistently promoted actions that individuals could take to protect themselves from the virus by wearing their face masks whenever they went out even as the cases of infections surged and the government grappled with space to quarantine infected persons; "all Ghanaians must remember that the wearing of masks is now mandatory. Leaving our homes without a face mask or face covering on is an offense ... the frontline is your front door."

Healthy lifestyle. The addresses also promoted a health strand that involved eating a balanced diet and having regular physical activities. The public was advised to eat locally produced foods such as millet, kontomire (cocoyam leaves), millet, cashew nuts, crabs, plantain, okra, brown rice, and mushroom which contained 
Vitamin A, B6, C, D, and E, to boost their immune system. The speeches also advised the public to engage in regular exercises because "it is crucial that we improve our fitness levels and adopt healthy eating practices that incorporate our local foodstuffs, which boost our immune systems."

Prevalence of the virus. This subtheme captured the extent to which the virus had spread in the country. All 14 speeches conveyed information about the number of confirmed cases recorded in the country: "At first glance, it is alarming to see that thirty-two thousand, nine hundred and sixty-nine $(32,969)$ people have so far contracted the virus." The speeches also indicated communities within the country with high prevalence and infection rates enabling the public to determine whether their communities were part of the infected areas or not, prompting any subsequent personal and group actions that were required to be taken.

Severity of the virus. This subtheme explained the seriousness of the virus. The speeches reported the number of deaths as a result of the virus to inform the public that the virus, if not taken seriously, could kill them. However, the speeches gave a positive impression that people were not dying as much as was initially feared when the country's death rates were compared to the global rate. "With 54 deaths currently reported by the Ghana Health Service thus far in Ghana, the ratio of deaths to positive cases stands at $0.4 \%$, compared to the global average of $5.5 \%$, and the African average of $2.6 \%$." Though the death rate was reported to communicate the seriousness of the virus, relatively higher recovery rates were recorded and reported to inform the public that infected persons could recover if they reported early to hospitals for testing, isolation, and treatment. This recovery rate information sought to encourage persons who experienced symptoms similar to those of the virus to get tested and treated if they tested positive.

Importation of the virus. This subtheme captured how or why the pandemic happened in the country. The speeches indicated that the virus was imported into the country by travelers returning from Europe, Asia, and neighboring countries like Burkina 
Faso, Ivory Coast, and Togo. "Seventy-nine percent (79\%) of the three hundred and seventy-eight (378) confirmed cases are, thus, imported. As has been established, the overwhelming majority of confirmed cases have come from travelers or from people who have come into contact with travelers." In addition to mandatory testing and treatment for all travelers, they had to undergo a mandatory 14-day quarantine.

\section{Sociocultural Dimension}

Under this broad theme, five subthemes emerged from the presidential addresses. Three subthemes evolved to enhance action steps the reader or viewer could take to mitigate any danger to their persons. They were staying at home, social distancing, and stigmatization. These three subthemes speak to the ethos of Ghanaians as warm and hospitable people. One subtheme emerged to express accountability and collective responsibility. Another subtheme emerged to express empathy and understanding of one's discomfort.

Staying at home. The president, in his speeches, ordered people living in most infected areas to stay at home. "If you must go out, it must only be to get essential items such as food, medicine, water, undertaking banking transactions, or to use public toilet facilities. But, as much as possible, stay at home." To ensure compliance, security personnel were deployed to enforce this order.

Social distancing. The speeches repeatedly encouraged the public to adhere to the social distancing protocol to protect themselves from the virus. Specifically, the speeches admonished the public to stop shaking hands (a phenomenon common in the Ghanaian culture) and avoid unnecessary close body contact. To ensure strict adherence to this protocol, the speeches announced the suspension of all public gatherings such as conferences, workshops, funerals, parties, nightclubs, drinking spots, beaches, festivals, political rallies, religious activities, and sporting events.

Stigmatization. This subtheme was directly lifted from the speeches because it accurately captured what was known about 
those who had recovered from the virus. People who had recovered from the virus were being stigmatized by their families and community members, and the president in four of his speeches sought to address those concerns.

I remain concerned about the stigma associated with this disease. Stories of persons who have recovered from this disease, and are being shunned by their relatives and communities, are a source of considerable worry to me because they undermine our efforts to fight it. There is nothing shameful about testing positive. We do not have to lose our sense of community because of this pandemic.

This statement sought to reinforce Ghanaian's sense of community, belonging, and oneness before the outbreak of the pandemic and to discourage the public from stigmatizing persons who had recovered from the virus. These speeches also recognized that the stigmatization was due to the public's fear that the recovered persons could infect others. As a way of dealing with that fear, these speeches provided scientific information from the WHO and scientists to prove that recovered persons could not infect others. "Persons, who have tested positive for the virus once they recover, do not pose any danger whatsoever to anyone because the scientists tell us that they can no longer spread the virus."

Collective responsibility. The speeches communicated the notion of collective responsibility to express accountability. The president frequently used first-person plural pronouns such as "we," "us," "our," and "ourselves" to indicate that the fight against the virus required all efforts from everyone. "This fight, fellow Ghanaians, cannot be that of Government alone. It is for all of us. We can defeat this virus if we all commit ourselves to respect all the measures that have been outlined." The speeches also described citizens who refused to adhere to the outlined social measures as unpatriotic. The description sought to suggest that such individuals did not love their country and were therefore not willing to sacrifice for 
the good of their country. This might to some extent cause public disaffection toward individuals seen not wearing face masks.

Understanding of one's discomfort. This theme expressed empathy about the threat of the pandemic to human health. The president acknowledged the disruptions this virus had brought to people's lives and therefore wished for an immediate return to normalcy. "Fellow Ghanaians, I, like you, would love to see an end to these restrictions. I know the difficulties each and every one of you has been through over the last two months. You had to alter completely your way of life. ..." Empathizing with the public, the president expressed that he stood by the people. In other words, he understood and shared their struggles through this difficult time. "We are in this together, and [the] Government will stand by you ... What we do not know how to do is to bring people back to life."

\section{Economic Dimension}

This overarching theme was developed through the provision of soft loans and food to vulnerable and needy people and the pledge for protection of lives emerging as an action step assuring citizens of the government's commitment.

Protection of lives. This subtheme reflected the president's commitment to fighting the pandemic. The speeches portrayed the determination of the president to protect the lives of teachers, students, and citizenry. " . . the oath of office I swore on 7 th January 2017 demands that I dedicate myself to the service and well-being of you, the Ghanaian people. It is my job to protect you, and I am determined to do just that." To prove that he was determined to protect lives and get the public's trust, the president frequently mentioned the distribution of protective equipment to frontline health workers and students. 


\section{Discussion}

Crisis and risk communicators have recommended best practices in crisis and emergency risk messaging that can make messages most effective for protecting public health during an emergency or crisis. The results of this study provide insights into some practical ways that can help public health and crisis communicators develop and disseminate health messages through presidential public speeches to inform the public about what they can do to protect themselves during a global pandemic. The findings show that all the seven best practices of crisis and emergency risk messages recommended by Parmer et al. (2016) were expressed in all 14 presidential speeches. At least three best practices were demonstrated in every speech that the Ghanaian president delivered. On the contrary, on average there were more than two best practices included in each media story found in Parmer et al's (2016) study. While their study found that the "empathy" best practice was expressed in the fewest stories, the "explain how or why" and "explain what is not known" best practices appeared in 2 of the 14 speeches-the least frequent of the seven best practices in the present study. A plausible explanation for the differences in frequency of the best practices in presidential addresses and media coverage may be the underlying values through which these contexts view or perceive emergencies or crises. For instance, media contents are primarily influenced by journalistic values such as prominence, proximity, currency, timeliness, conflict, human interest, and bizarreness (Boyd, 1994). On the other hand, political values (such as order, liberty, and caring for those who need help) most likely influence the contents of presidential public addresses or speeches (Swedlow, 2008).

Specifically, empathy was frequently used in 11 of the 14 speeches to indicate that the government understood the disruption this pandemic had brought to the lives of the public, and they (the government) would stand by them. This indicates care for the citizens. The broad literature on crisis and emergency risk communication argues that empathy and caring (i.e., words that acknowledge what people are feeling) help to build public trust, making it easy for public health communicators to effectively persuade the 
public to take recommended actions to protect themselves during a pandemic (B. Reynolds et al., 2002; B. J. Reynolds, 2011; Seeger, 2006). This study also found that the presidential speeches recommended some simple tasks (e.g., wearing a mask, washing hands with soap under running water, staying at home, eating a balanced diet, exercising regularly, etc.) that the public could take to protect themselves from the virus. Previous research indicates that such simple tasks would "help people gain back a sense of control and help keep them motivated to stay tuned to what is happening" during a crisis or emergency (CDC, 2014, p. 41).

Furthermore, this study found that the "explain what is known" and "promote action steps" best practices appeared in all 14 speeches. Previous works revealed that instructional risk and crisis messages designed based on the IDEA model emphasizing elements of internalization, explanation, and action effectively encouraged participants to engage in self-protective behaviors during food crises (D. D. Sellnow et al., 2015; D. D. Sellnow et al., 2017; \& D. D. Sellnow et al., 2019). The implication is that the presidential speeches might have been effective in encouraging the public to take the recommended behaviors (e.g., mask-wearing, social distancing, or handwashing) to protect themselves from the virus. However, the infrequent appearance of the "explain how or why" and "explain what is not known" best practices in the presidential speeches suggests that the public might have limited information or knowledge about factors that caused the pandemic to happen. This might be counterproductive to messages encouraging self-protective behaviors. The study also found that social stigma against COVID-19 recovered patients was addressed in the presidential speeches. Studies on social stigma argue that stigmatization associated with highly contagious diseases can significantly increase internal sufferings of infected persons as well as discourage infected or suspected infected persons from seeking health care, making the containment of such diseases extremely difficult (Budhwani \& Sun, 2020; Parker \& Aggleton, 2003; Ramaci et al., 2020).

Notably, the presidential speeches provided scientific information to reassure the public that recovered persons could no longer infect others. According to Misra and colleagues (2020), promoting 
effective messages against COVID-19 related stigma could help to deal with any misinformation associated with this pandemic. Though the presidential speeches strongly spoke against social stigma associated with recovered persons, the speeches' consistent mention of importation of the virus in the country seemed to implicitly portray travelers, especially from Europe, as carriers of the virus. This might have implicitly encouraged social stigma against persons who had recently returned from abroad. Supporting this finding, Logie and Turan (2020) contend that "COVID19 travel restrictions may also facilitate stigma and xenophobia by reproducing the social construction of illness as a foreign invasion, in turn reinforcing social hierarchies and power inequalities" (p. 2004).

Additionally, the crisis communication literature suggests that organizations or agencies should communicate their intentions to their stakeholders (i.e., public or audience) by explicitly showing commitment to stand with their publics throughout the crisis (CDC, 2014; B. J. Reynolds, 2011). This can be done by "stating upfront, your organization's objectives for the emergency response and committing to reaching them" (CDC, 2014, p. 55). This study found that the speeches consistently mentioned the government's five key objectives of responding to this pandemic: "limit and stop the importation of the virus; contain its spread; provide adequate care for the sick; limit the impact of the virus on social and economic life; and inspire the expansion of our domestic capability and deepen our self-reliance." The speeches demonstrated this commitment through the government's provision of protective equipment to all healthcare workers, food for individuals and homes in affected areas of restrictions, soft loans for micro-, small-, and medium-sized local business, and absorption of water and electricity bills for all citizens.

\section{Theoretical Implications}

Though the crisis and emergency risk communication is not a theory per se, it is an integrative model that has been "validated by the experiences of health communicators and public affairs specialists who have completed the training, conducted the training, 
and executed the principles ..." (Veil et al., 2008, p. 29S). Veil and colleagues call it a grounded theory. They argue that risk messages influence public perceptions, expectations, and behavior during a crisis. As a contribution, this study demonstrates that presidential public speeches could be used to shape public risk perceptions about their vulnerability to the virus and how severe the virus could become if not taken seriously during a pandemic. The literature on belief models suggests that individuals would take actions to avoid unpleasant occurrences if they believed that it was likely to happen to them and it would be severe (Rosenstock, 1974). Veil et al. also propose that risk reduction during crises should be systematically examined; and psychological research suggests that when people's feelings of fear, anxiety, or dread are not effectively managed during a crisis, they most likely feel hopeless or helpless (Benight \& Bandura, 2004; CDC, 2014). The present findings demonstrate that the public's heightened fear or anxiety about the severity of a virus during a pandemic could be reduced by giving them hope through public health messages that infected persons could recover when tested early and received early treatment after testing positive.

Furthermore, the broad literature on crisis communication explains accountability as "being accountable for the decisions you make and the outcomes that arise from those decisions. The public and interested stakeholders will expect organizations to keep their promises-stated and implicit” (B. J. Reynolds, 2011, p. 210). Expanding on this definition of accountability, this study's findings articulate that public health messages through presidential addresses could encourage the public to be accountable to themselves by adhering to protective measures during a pandemic. Public health messages could characterize individuals refusing to adhere to protective measures as unpatriotic. Portraying or framing such unpatriotic individuals as unwilling to sacrifice for the good and safety of their country could potentially motivate most people to adhere to recommended protective measures. Additionally, this study demonstrates that first-person plural pronouns such as "we," "us," "our," and "ourselves" could be used in public health messages to communicate the notion of collective responsibility to 
make the public feel more accountable to themselves and others during a pandemic. This messaging approach could be most effective and persuasive in collectivist cultures or societies which tend to "emphasize loyalty to the group ..." (Darwish \& Huber, 2003, p. 49). In collectivist societies, people are more concerned about the needs and interests of others than themselves; and this concern for others influences individuals' decisions and actions in a society (Darwish \& Huber, 2003; Eaton \& Louw, 2000; LeFebvre \& Franke, 2013). During a global pandemic where individuals' actions (such as mask-wearing, social distancing, or handwashing with soap under running water) significantly impact others, highlighting the concern for protecting others in public health messages would most likely influence the public to take recommended actions in collectivist societies. Ghana is a collectivist society (LeFebvre \& Franke, 2013); thus, the speeches employed first-person plural pronouns to encourage the public to feel more accountable to others (the collective interest) by wearing their nose masks, practicing social distance, avoiding handshakes, washing their hands with soap under running water, and so forth.

\section{Practical Implications}

This study's findings provide some practical insights for effective crisis and emergency risk messaging during a pandemic. First, public health messages should promote simple action steps that the public could take to protect themselves. According to social cognitive research, perceived self-efficacy can either enhance or hinder cognitive processes such that individuals with low selfefficacy would experience stress when faced with a difficult task (Bandura, 1991 \& 1994). Thus, during a pandemic where the majority of people with different levels of perceived self-efficacy are impacted, public health communicators should promote protective actions that are easy and simple for most people to take on their own. Seeger (2006) suggests that self-efficacy messages should contain clear and meaningful actions and be consistent as well. Second, public health communicators should take proactive steps to promote effective messages that address social stigma during a global pandemic. For example, stigma-reduction 
messages promoting social distancing should be designed in ways that "foster empathy while simultaneously transforming physical distancing into a normal and sustained practice until the pandemic is over" (Logie \& Turan, 2020, p. 2004). Also, the findings show that there are different layers of the stigma associated with the COVID-19 pandemic (i.e., stigmatization of infected persons and travelers). Recent research shows COVID-19 related stigma associated with Asians (Budhwani \& Sun, 2020). Thus, a multiapproach to effective messaging should be developed and disseminated to address different stigma issues during a pandemic. Lastly, public health communicators should carefully consider the media or channels through which crisis and emergency risk messages are disseminated. The findings indicate that different channels have different values that influence their message content. These varied values largely determine which best practices are emphasized in public health messages. D. D. Sellnow et al. (2017) suggest "traditional media channels remain an effective means for communicating instructional risk and crisis messages and should not be discounted" (p. 13).

\section{Limitations and Future Research Directions}

Due to the deductive nature of this study (i.e., using Parmer et al's (2016) recommended seven crisis and emergency risk messaging best practices), we could not examine the language of the presidential speeches. Research based on CERC indicates that communicating messages full of technical jargon and euphemism during crises implies "insecurity and lack of honesty" (CDC, 2014, p. 56). Avoiding them helps build trust with the audience or the public (CDC, 2014). Further, crisis communicators suggest that crisis messages must account for limitations in literacy and numeracy among the target population, so the content of the message is easily understood by all (D. D. Sellnow, 2015). Hence, a 6th-grade reading and comprehension level has been recommended (CDC, 2014). Future research should examine the language used in presidential speeches during pandemics. Another limitation of this study was that we only focused on the written speeches and did not look at the delivery aspect (both verbal and non-verbal) of 
these speeches. Crisis communication research and practice recommend that spokespersons should "convey calmness and confidence through posture, tone of voice, facial expressions, and gestures" to help their audience to "remain calm and confident in their own actions" (CDC, 2014, p. 68). Future research should examine the delivery (both verbal and non-verbal) of presidential speeches during pandemics.

\section{Conclusion}

The study has provided insightful information on how global pandemics can be communicated from a developing country context. Contrary to Parmer et al.s (2016) findings but in sync with their seven crisis and emergency risk messaging best practices, this study concludes that appropriate expression of empathy; concise, systematic, and simple risk communication messages; and a sense of community gleaned through individual and collective accountability could mitigate the effects of social stigma. This could also act as a balm to the public's psyche on the COVID-19 pandemic, culminating in better management of pandemics.

\section{ORCID}

Prince Adu Gyamfi () https://orcid.org/oooo-0003-0047-5359 Adwoa Sikayena Amankwah (i) https://orcid.org/oooo-00025106-0746

\section{References}

Andrade, L. E., Barrett, N. D., Edberg, M. C., Rivera, M. I., Latinovic, L., Seeger, M. W., Goldman-Howes, A., \& Santos-Burgoa, C. (2020). Mortality reporting and rumor generation: An assessment of crisis and emergency risk communication following Hurricane Maria in Puerto Rico. Journal of International Crisis and Risk Communication Research, 3(1), 15-48. https://doi. org/10.30658/jicrcr.3.1.2 
Balog-Way, D. H. P., \& McComas, K. A. (2020). COVID-19: Reflections on trust, tradeoff, and preparedness. Journal of Risk Research, 23(7-8), 838-848. https://doi.org/10.1080/13669877 .2020 .1758192

Bandura, A. (1991). Self-efficacy mechanism in physiological activation and health-promoting behavior. In J. Madden, IV (Ed.), Neurobiology of learning, emotion and affect (pp. 229-270). Raven.

Bandura, A. (1994). Self-efficacy. In V. S. Ramachaudran (Ed.), Encyclopedia of human behavior (Vol. 4, pp. 71-81). Academic Press.

Benight, C. C., \& Bandura, A. (2004). Social cognitive theory of posttraumatic recovery: The role of perceived self-efficacy. Behavioral Research and Therapy, 42(10), 1129-1148. https:// doi.org/10.1016/j.brat.2003.08.008

Boyd, A. (1994). Broadcasting journalism: Techniques of radio and TV news. Focal Press.

Braun, V., \& Clarke, V. (2006). Using thematic analysis in psychology. Qualitative Research in Psychology, 3, 77-101. https://doi. org/10.1191/1478088706qpo63oa

Budhwani, H., \& Sun, R. (2020). Creating COVID-19 stigma by referencing the novel coronavirus as the "Chinese virus" on Twitter: Quantitative analysis of social media. Journal of Medical Internet Research, 22(5), e19301. https://doi. org/10.2196/19301

CDC. (2014). Crisis and emergency risk communication manual. https://web.archive.org/web/20210120202720/https:// emergency.cdc.gov/cerc/manual/index.asp

CDC. (2020). "Coronavirus disease 2019 (COVID-19)." Accessed 26 May 2020. https://www.cdc.gov/coronavirus/2019-ncov/ global-covid-19/world-map.html

Coombs, W. T. (2009). Conceptualizing crisis communication. In R. L. Health \& H. D. O'Hair (Eds.), Handbook of risk and crisis communication (pp. 31-52). Routledge.

Darwish, A. E., \& Huber, G. L. (2003). Individual vs collectivism in different cultures: A cross-cultural study. Intercultural Education, 14(1), 47-56. https://doi.org/10.1080/1467598032 000044647 
Eaton, L., \& Louw, J. (2000). Culture and self in South Africa: Individualism-collectivism predictions. The Journal of Social Psychology, 140(2), 210-217. https://doi. org/10.1080/00224540009600461

Fischhoff, B., \& Kadvany, J. (2011). Risk: A very short introduction. Oxford University Press.

Henrich, J., Heine, S. J., \& Norenzayan, A. (2010). The weirdest people in the world? Behavioral \& Brain Science, 33, 61-135. https://doi.org/10.1017/So140525X0999152X

LeFebvre, R., \& Franke, V. (2013). Culture matters: Individualism vs. collectivism in conflict decision-making. Societies, 3, 128146. https://doi.org/10.3390/soc3010128

Lincoln, Y. S., \& Guba, E. G. (1985). Naturalistic inquiry. SAGE.

Logie, C. H., \& Turan, J. M., (2020). How do we balance tensions between COVID-19 public health responses and stigma mitigation? Learning from HIV research. AIDS and Behavior, 24, 2003-2006. https://doi.org/10.1007/s10461-020-02856-8

Merriam, S. B., \& Tisdell, E. J. (2016). Qualitative research: A guide to design and implementation (4th ed.). Jossey Bass.

Miles, M. B., \& Huberman, A. M. (1994). Qualitative data analysis: An expanded sourcebook (2nd ed.). Sage.

Misra, S., Le, P. T. D., Goldmann, E., \& Yang, L. H. (2020). Psychological impact of anti-Asian stigma due to the COVID19 pandemic: A call for research, practice, and policy. Psychological Trauma: Theory, Research, Practice, and Policy, 12(5), 461-464. https://doi.org/10.1037/traoooo821

Palenchar, M. J. (2009). Historical trends of risk and crisis communication. In R. L. Health \& H. D. O'Hair (Eds.), Handbook of risk and crisis communication (pp. 31-52). Routledge.

Parker, R., \& Aggleton, P. (2003). HIV and AIDS-related stigma and discrimination: A conceptual framework and implications for action. Social Science \& Medicine, 57, 13-24. https://doi. org/10.1016/s0277-9536(02)00304-0

Parmer, P., Baur, C., Eroglu, D., Lubell, K., Prue, C., Reynolds, B., \& Weaver, J. (2016). Crises and emergency risk messaging in mass media news stories: Is the public getting the information they need to protect their health? Health Communication, 31(10), 1215-1222. https://doi.org/10.1080/10410236.2015.10 49728 
Quinn, S. C. (2008). Crisis emergency risk communication in a pandemic: A model for building capacity and resilience of minority communities. Health Promotion Practice, 9(4), 18S25S. https://doi.org/10.1177/1524839908324022

Ramaci, T., Barattucci, M., Ledda, C., \& Rapisarda, V. (2020). Social stigma during COVID-19 and its impact on HCWs outcomes. Sustainability, 12(9), 3834. https://doi.org/10.3390/ su 12093834

Reynolds, B. (2002). Crisis and emergency risk communication. Centers for Disease Control and Prevention.

Reynolds, B., Galdo, J., \& Sokler, L. (2002). Crisis and emergency risk communication. Centers for Disease Control and Prevention.

Reynolds, B., \& Quinn, S. C. (2008). Effective communication during an influenza pandemic: The value of using a crisis and emergency risk communication framework. Health Promotion Practice, 9(4), ${ }_{13} \mathrm{~S}-17 \mathrm{~S}$. https://doi. org/10.1177/1524839908325267

Reynolds, B., \& Seeger, M. W. (2005). Crisis and emergency risk communication as an integrative model. Journal of Health Communication, 10, 43-55. https://doi. org/10.1080/10810730590904571

Reynolds, B. J. (2011). When the facts are just not enough: Credibility communicating about risk is riskier when emotions run high and time is short. Toxicology and Applied Pharmacology, 254, 206-214. https://doi.org/10.1016/j.taap.2010.10.023

Rosenstock, I. M. (1974). Historical origins of the health belief model. Health Education Monographs, 2, 328-335. https://doi. org/10.1177/109019817400200403

Seeger, M. W. (2006). Best practices in crisis communication: An expert panel process. Journal of Applied Communication Research, 34(3), 232-244. https://doi.org/10.1080/00909880 600769944

Seeger, M. W., Reynolds, B., \& Sellnow, T. L. (2009). Crisis and emergency risk communication in health contexts: Applying the CDC model to pandemic influenza. In R. L. Health \& D. H. O'Hair (Eds.), Handbook of risk and crisis communication (pp. 493-506). Routledge. 
Sellnow, D. D., Johansson, B., Sellnow, T. L., \& Lane, D. R. (2019). Toward a global understanding of the effects of the IDEA model for designing instructional risk and crisis messages: A food contamination experiment in Sweden. Journal of Contingencies and Crisis Management, 27, 102-115. https:// doi.org/10.1111/1468-5973.12234

Sellnow, D. D., Lane, D., Littlefield, R. S., Sellnow, T. L., Wilson, B., Beauchamp, K., \& Venette, S. (2015). A receiver-based approach of effective instructional crisis communication. Journal of Contingencies and Crisis Management, 23(3), 149158. https://doi.org/10.1111/1468-5973.12066

Sellnow, D. D., Lane, D. R., Sellnow, T. L., \& Littlefield, R. S. (2017). The IDEA model as a best practice for effective instructional risk and crisis communication. Communication Studies, 68(5), 552-567. https://doi.org/10.1080/10510974.2017.1375535

Sellnow, T., \& Sellnow, D. (2010). The instructional dynamic risk and crisis communication: Distinguishing instructional messages from dialogue. The Review of Communication, 1o(2), 112-126. https://doi.org/10.1080/15358590903402200

Sellnow, T. L. (2015). Crisis communication. In H. Cho, T. Reimer, \& K. A. McComas (Eds.), The SAGE handbook of risk communication (pp. 288-302). SAGE Publications.

Sellnow, T. L., \& Seeger, M. W. (2013). Theorizing crisis communication. Wiley-Blackwell.

Sellnow, T. L., \& Sellnow, D. D. (2013, July). The role of instructional risk messages in communicating about food safety. Food insight: Current topics in food safety and nutrition (p. 3). International Food Information Council Foundation.

Swedlow, B. (2008). Beyond liberal and conservative: Twodimensional conceptions of ideology and the structure of political attitudes and values. Journal of Political Ideologies, 13(2), 157-18o. https://doi.org/10.1080/13569310802075969

Vanderford, M. L., Nastoff, T., Telfer, J. L., \& Bonzo, S. E. (2007). Emergency communication challenges in response to Hurricane Katrina: Lessons from the centers for disease control and prevention. Journal of Applied Communication Research, 35(1), 9-25. https://doi.org/10.1080/00909880601065649 
Vaughan, E., \& Tinker, T. (2009). Effective risk communication about pandemic influenza for vulnerable populations. American Journal of Public Health, 99(2), S324-S332. https:// doi.org/10.2105/AJPH.2009.162537

Veil, S., Reynolds, B., Sellnow, T. L., \& Seeger, M. W. (2008). CERC as a theoretical framework for research and practice. Health Promotion Practice, 9(4), 26S-34S. https://doi. org/10.1177/1524839908322113

WHO. (2020). "Surveillance strategies for COVID-19 human infection." Retrieved May 26, 2020, from https://web.archive. org/web/20200526192935/https://www. who.int/publications-detail/surveillance-strategies-for-covid-19-human-infection

WHO. (2021). "Coronavirus disease (COVID-19) dashboard." Retrieved February 5, 2021, from https://web.archive.org/ web/20210205125819/https://covid19.who.int/table/ 

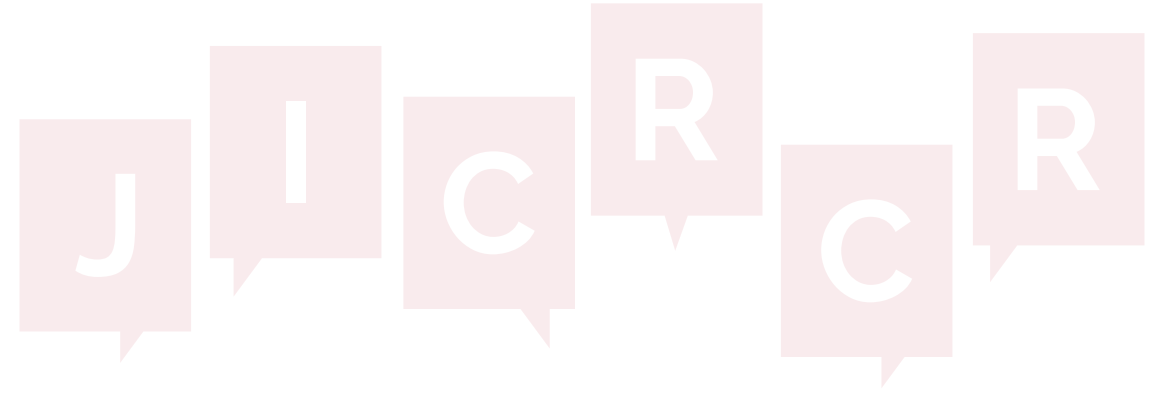